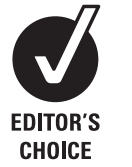
ITOR'S
CHOICE

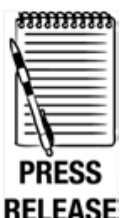

RELEASE

\title{
School children's backpacks, back pain and back pathologies
}

\author{
Paloma Rodríguez-Oviedo, ${ }^{1}$ Alberto Ruano-Ravina, ${ }^{2,3}$ Mónica Pérez-Ríos, ${ }^{2}$ \\ Francisco Blanco García, ${ }^{4}$ Dorotea Gómez-Fernández, ${ }^{1}$ Anselmo Fernández-Alonso, ${ }^{1}$ \\ Isabel Carreira-Núñez, ${ }^{1}$ Pilar García-Pacios, ${ }^{1}$ Javier Turiso ${ }^{5}$
}

${ }^{1}$ Emergency Service, Hospital da Costa, Burela, Spain 2Department of Preventive Medicine and Public Health, University of Santiago de Compostela, Santiago de Compostela, Spain ${ }^{3}$ CIBER de Epidemiología y Salud Pública, CIBERESP, Spain

${ }^{4}$ Rheumathology Service, University Hospital Complex of A Coruña, La Coruña, Spain ${ }^{5}$ Department of Traumatology, University Hospital Son Dureta, Palma de Mallorca, Spain

\section{Correspondence to} Professor Alberto Ruano Raviña, Department of Preventive Medicine and Public Health, School of Medicine, C/ San Francisco $\mathrm{s} / \mathrm{n}$, University of Santiago de Compostela, Santiago de Compostela CP 15782 .

La Coruña, Spain; alberto ruano@usc.es

Received 24 October 2011 Accepted 29 January 2012 Published Online First 10 March 2012

\section{ABSTRACT}

Objective To investigate whether backpack weight is associated with back pain and back pathology in school children.

Design Cross-sectional study.

Setting Schools in Northern Galicia, Spain.

Patients All children aged 12-17.

Interventions Backpack weight along with body mass index, age and gender.

Main outcome measures Back pain and back pathology.

Results 1403 school children were analysed. Of these, $61.4 \%$ had backpacks exceeding $10 \%$ of their body weight. Those carrying the heaviest backpacks had a $50 \%$ higher risk of back pain (OR $1.50 \mathrm{Cl} 95 \% 1.06$ to 2.12) and a $42 \%$ higher risk of back pathology, although this last result was not statistically significant (OR 1.42 $\mathrm{Cl} 95 \% 0.86$ to 2.32). Girls presented a higher risk of back pain compared with boys.

Conclusions Carrying backpacks increases the risk of back pain and possibly the risk of back pathology. The prevalence of school children carrying heavy backpacks is extremely high. Preventive and educational activities should be implemented in this age group.

\section{INTRODUCTION}

Back pain is currently a health problem of school children which can limit daily-life activities. Sedentary lifestyle is possibly the most important factor determining back pain among school children. According to the 2006 Spanish National Health Enquiry, $11.8 \%$ of students aged 10-15 classified themselves as sedentary. ${ }^{1}$ Sedentarism along with lack of physical activity contributes to a lower muscular tonicity of the back. Some studies have shown that an individual with back pain in adolescence is more likely to develop low back pain in adult life or that heavy backpacks can cause neck, shoulders and back muscular problems, such as scoliosis. $^{2}{ }^{3}$ Experts recommend that school children should not carry loads exceeding $10 \%$ of their body weight. 4

The objective of this study is to analyse the influence of backpack weight on back pain and back pathologies.

\section{SUBJECTS AND METHODS}

This is a cross-sectional analytic study among school children aged 12-17 for the academic year 2005-2006 in Northern Spain. Eleven schools in the area took part in the study.

\section{What is already known on this topic}

- School backpacks have been associated with back pain and it is thought that they can create back pathology in adult life.

- Prevalence in back pain and backpack weight of school children is highly variable among countries.

- There are very few studies analysing the relationship among backpack weight and back pathology in school children.

\section{What this study adds}

- In all, $61.4 \%$ and $18.1 \%$ of participants carried backpacks exceeding $10 \%$ and $15 \%$ of their body weight, respectively.

- Those carrying the heaviest backpacks presented a $50 \%$ higher risk of back pain and a close to significant risk of back pathology.

School children were weighed twice on digital scales with an integrated height metre (SECA 764, Spain); the first time without overcoats and objects posing an extra weight (such as mobile phones, keys, coins) but with the backpack they were carrying that day and the second time without the backpack. Height was obtained placing children's backs against the height metre with joint heels. The weighting day was known by academic authority but not by school children and it was randomly chosen.

School children's parents or legal tutors fulfilled a questionnaire on their children's lifestyle with special emphasis on frequency of sports activities (at school) and duration of sedentary activities performed at home. Presence of a lesion or pathology previously diagnosed by a physician (such as scoliosis, kyphosis) and presence of back pain for more than 15 days in the previous year were also ascertained.

We compared the characteristics of initially included school children with those finally analysed. Two logistic multivariate models were used, having each one as the main dependent variable the presence or absence of pain during more than 15 days in the previous year and the presence or absence of back pathology. In both models, the main independent variable was 
Table 1 Relationship between the school bag weight and back pain for more than 15 days

\begin{tabular}{|c|c|c|c|}
\hline \multirow[t]{2}{*}{ Variable } & \multicolumn{2}{|c|}{ Back pain n (\%) } & \multirow[t]{2}{*}{ OR (CI 95\%) } \\
\hline & No & Yes & \\
\hline \multicolumn{4}{|l|}{ School bag weight } \\
\hline First quartile & $248(23.9)$ & $83(22.8)$ & 1 \\
\hline Second quartile & $278(26.8)$ & $87(23.9)$ & $1.0(0.7$ to 1.4$)$ \\
\hline Third quartile & $258(24.8)$ & $85(23.4)$ & $1.1(0.7$ to 1.5$)$ \\
\hline Fourth quartile & $255(24.5)$ & $109(29.9)$ & 1.5 (1.1 to 2.1$)$ \\
\hline \multicolumn{4}{|l|}{ Body mass index } \\
\hline First quartile & $268(25.8)$ & $87(23.9)$ & 1 \\
\hline Second quartile & $264(25.4)$ & $82(22.5)$ & $0.8(0.6$ to 1.2$)$ \\
\hline Third quartile & $257(24.7)$ & $96(26.4)$ & $1.0(0.7$ to 1.4$)$ \\
\hline Fourth quartile & $250(24.1)$ & $99(27.2)$ & $1.1(0.8$ to 1.5$)$ \\
\hline \multicolumn{4}{|c|}{ Perform some type of sports activity } \\
\hline No & $472(45.7)$ & $181(49.7)$ & 1 \\
\hline Yes & $561(54.3)$ & $183(50.3)$ & $1.0(0.8$ to 1.3$)$ \\
\hline \multicolumn{4}{|l|}{ Sex } \\
\hline Boy & $528(50.8)$ & $145(39.8)$ & 1 \\
\hline Girl & $511(49.2)$ & $219(60.2)$ & $1.6(1.3$ to 2.1$)$ \\
\hline Age (continuous variable) & - & & $1.2(1.1$ to 1.3$)$ \\
\hline
\end{tabular}

the school bag weight classified in quartiles. Adjustment variables were gender, age (continuum), body mass index (quartiles) and sport activities (yes/no). Results were obtained with Statistical Package for the Social Sciences, v17.0 (SPSS). The Burela Hospital Ethics Committee approved the study protocol.

\section{RESULTS}

The sample initially included 2135 school children and 1403 $(65.7 \%)$ were analysed. There were no differences between analysed and excluded school children. The mean age of participants was 14 years and $92.2 \%$ used a backpack with two shoulder straps. Mean school bag weight was nearly $7 \mathrm{~kg}$. In all, $61.4 \%$ of participants carried school bags exceeding $10 \%$ of their body weight and $18.1 \%$ exceeded the $15 \%$ of their body weight; $25.9 \%$ reported to have had back pain for more than 15 days in the previous year. The most frequent pathology was scoliosis (70\% of the pathologies reported) followed by low back pain and contractures (10\% each).

Participants carrying school bags on the highest quartile had a $50 \%$ higher risk of back pain for more than 15 days $(\mathrm{OR}=1.50 \mathrm{CI} 95 \% 1.06$ to 2.12$)$ (table 1$)$. Girls had a higher risk of back pain and an increased risk with age was observed. When analysing the relationship between school bag weight and back pathology there was a non-significant association for those weights on the highest quartile (OR=1.42 CI 95\% 0.86 to 2.32). Girls had a higher risk of back pathology and the risk of back pathology was observed to increase with age (table 2).

\section{DISCUSSION}

Children carrying the heaviest backpacks have a higher risk of suffering from back pain and a higher risk of back pathology. Most school children carry backpacks exceeding the recommended weights.

Many studies have found that backpacks alter posture and gait significantly, produce modifications in the head-neck angle, shoulder asymmetry and even lumbar lordosis. These biomechanical alterations could induce the appearance of chronic pain and back pathologies in the long term.
Table 2 Relationship between the school bag weight and back pathology

\begin{tabular}{|c|c|c|c|}
\hline \multirow[t]{2}{*}{ Variable } & \multicolumn{2}{|c|}{ Back pathology $n(\%)$} & \multirow[t]{2}{*}{ OR (CI 95\%) } \\
\hline & No & Yes & \\
\hline \multicolumn{4}{|l|}{ School bag weight } \\
\hline First quartile & $297(23.7)$ & $34(22.8)$ & 1 \\
\hline Second quartile & $325(25.9)$ & $40(26.8)$ & $1.2(0.7$ to 1.9$)$ \\
\hline Third quartile & $311(24.8)$ & $32(21.5)$ & $1.0(0.6$ to 1.7$)$ \\
\hline Fourth quartile & $321(25.6)$ & $43(28.9)$ & $1.4(0.9$ to 2.3$)$ \\
\hline \multicolumn{4}{|l|}{ Body mass index } \\
\hline First quartile & $321(25.6)$ & $34(22.8)$ & 1 \\
\hline Second quartile & $307(24.5)$ & $39(26.2)$ & $1.1(0.6$ to 1.7$)$ \\
\hline Third quartile & $314(25.0)$ & $39(26.2)$ & $1.0(0.6$ to 1.6$)$ \\
\hline Fourth quartile & $312(24.9)$ & $37(24.8)$ & $1.0(0.6$ to 1.6$)$ \\
\hline \multicolumn{4}{|c|}{ Perform some type of sports activity } \\
\hline No & $584(46.8)$ & $69(46.3)$ & 1 \\
\hline Yes & $664(53.2)$ & $80(53.7)$ & $1.2(0.8$ to 1.7$)$ \\
\hline \multicolumn{4}{|l|}{ Sex } \\
\hline Boy & $612(48.8)$ & $61(40.9)$ & 1 \\
\hline Girl & $642(51.2)$ & $88(50.1)$ & $1.5(1.0$ to 2.2$)$ \\
\hline Age (continuous variable) & - & & $1.3(1.1$ to 1.4$)$ \\
\hline
\end{tabular}

Between $20 \%$ and $45 \%$ of young people aged $14-18$ have back pain for more than 15 days. A study performed in Northeast England in 2002 showed a low back pain prevalence of $24 \%$, with girls posing a higher prevalence compared with boys. ${ }^{5}$ Another study performed in Italy by Negrini and Negrini ${ }^{3}$ found that 11 -year-old children carried backpacks as heavy as $20 \%$ of their body weight, and also that $58.4 \%$ had experienced back pain more than once in their lifetime.

Girls are more prone to experience back pain and back pathology than boys, although there are no differences on backpack weight by gender. Grimmer et al ${ }^{6}$ observed that girls were more prone to have changes in the craniovertebral angle when carrying a backpack and this association became stronger with age.

The cross-sectional design of the present study is a limitation, as it limits the causal inference of its findings. In this type of study, it is difficult to measure past events such as pain lasting more than 15 days. Other factors that have not been studied such as poor physical fitness, poor back posture, structural scoliosis and hypermobility cannot be excluded as the real cause of back pain. It is possible that backpacks were carried frequently with one strap instead of two with this fact acting jointly with weight in back pain incidence. The strength of this study is the sample size, which allows for precise estimations adjusted by sex, age, body mass index and sports activity.

The results obtained have strong implications. Many children transport excessively loaded backpacks, an excess which would not be allowed for workers in employment. We strongly encourage the medical and educational community to start advising parents and school children about the risks posed by heavy school bags and the fact that this risk can be easily reduced.

Contributors All authors contributed equally to the writing of the manuscript. PRO, ARR, FBG and MPR designed the study. DGF, AFA and ICN performed the statistical analysis. All authors interpreted the results and discussed the most relevant information to be communicated.

Competing interests None.

Ethics approval Approval provided by the Burela Hospital Ethics Committee.

Provenance and peer review Not commissioned; externally peer reviewed. 


\section{REFERENCES}

1. Encuesta Nacional de Salud. Ministerio de Sanidad y Política Social. Gobierno de España, 2006

2. Hestbaek L, Leboeuf-Yde C, Kyvik KO, et al. The course of low back pain from adolescence to adulthood: eight-year follow-up of 9600 twins. Spine 2006;31:468-72.

3. Negrini S, Negrini A. Postural effects of symmetrical and asymmetrical loads on the spines of schoolchildren. Scoliosis 2007;2:8.
4. Chow DH, Kwok ML, Au-Yang AC, et al. The effect of backpack load on the gait of normal adolescent girls. Ergonomics 2005;48:642-56.

5. Watson KD, Papageorgiou AC, Jones GT, et al. Low back pain in schoolchildren: occurrence and characteristics. Pain 2002;97:87-92.

6. Grimmer KA, Williams MT, Gill TK. The associations between adolescent headon-neck posture, backpack weight, and anthropometric features. Spine (Phila Pa 1976) 1999;24:2262-7. 